\title{
Comparing the energy efficiency of exterior shading by metal slats and mesh screens in an early phase design exercise for an office building in Bucharest
}

\author{
Ioana Udrea $^{1, *}$, and Romeo Popa $^{2}$ \\ ${ }^{1}$ ASC-Romania, 9 Stefan Marinescu Street, District 6, 060121, Bucharest, Romania \\ 2 Polytechnic University of Bucharest, Faculty of Mechanical Engineering and Mechatronics, Thermodynamics Department, 313 Spl. \\ Independentei 313, District 6, 060042, Bucharest, Romania
}

\begin{abstract}
An early phase design exercise for shading a South facade of an office building in Bucharest is presented here. The problem to solve is deciding in a simple and quick way (not using the complicated BSDF approach), based strictly on energy-efficiency considerations, between two options in principle: the first, exterior screens, is much cheaper and the send is unmovable horizontal aluminium slats. The tool used to produce the necessary result quantities by building energy simulation is COMFEN 4.1. The conclusion is positive: if aesthetic reasons are ignored, in Bucharest and very likely many other Romanian cities having a quite similar climate, screens can be at least equally effective in saving energy by South facade shading. As they allow a flexible shading strategy (removing them during some months of the heating season), the energyefficiency realized by having them on throughout the year can be increased further.
\end{abstract}

\section{Introduction}

The first phase of building design, the so-called early design, is very important for the energy performance of the future building. Because major decisions in that respect are now made. We share the philosophy stated in [1]: 'The envelope should be the first method of creating low-energy buildings; the mechanical and lighting systems should then be sized to meet any remaining loads. Low-energy architecture is not effective if mechanical systems have to solve problems that result from the architectural design'. At the same time, calculations of this early phase should not be very complicated and should not use many and detailed building inputs. This thing has always been a requirement in order to have the design process fast and low-cost and accessible to most designers (in general architects, who of course prefer to keep to a minimum involving people with additional expertise in their work). The facade and generally the envelope of the building can bring a significant contribution to its energy performance. And various aspects of facade design related to its energy efficiency (one of which is facade shading), should be approached at this stage. This paper presents a small calculation exercise as part of the early design phase of the facade of a mid-rise office building in Bucharest. It evaluates if a cheaper exterior shading system (exterior screen) can be as good, from an energy-efficiency point of view, as a more expensive one (exterior aluminum slats). As a matter of fact, the analysis done is afterconstruction; that is, the respective building is already built and its South facade is shaded by a fixed (sometimes also called passive) system made of aluminum louvers (macro slats) spanning the facade length (see Fig. 1). So, what we want to estimate by a very simple and quick analysis process, whose results are not excessively precise and detailed, is if the cheaper alternative (exterior screens) is a choice at least equally energy-efficient. The adopted analysis manner might be applicable where building space daylight is not a primary concern and consequently it can be disregarded in an early phase of the iterative design process that mainly focuses on energy-efficiency.

It has been documented since about $2000[2,3]$ that the best energy efficiency choice for building shading is an exterior shading device. Two main categories of such devices are slats and screens. Slats can be quite wide (more than several $\mathrm{cm}$ ) and are then referred to as louvers or macro slats or smaller, in which case they are mostly called slats or blinds. Screens can be rigid, of the panel type or flexible and then they are also called meshes. There are two main avenues to model shading systems in building energy simulation, an "old" and a "new" one. The "old" models consider in general the surfaces of the shading system to be perfect diffusers, isotropically scattering solar radiation after interacting with it. The "novelty", a more precise modeling of the whole system composed of glazing and shading devices, is called the Bidirectional Scattering Distribution Function (BSDF) procedure $[4,5,6]$. In it, both the entire assembly (called complex fenestration system) and the component "layers" of the glazing and shading system are characterized by

* Corresponding author: ioana.udrea $@$,asc-ro.com 
their angular transmission and reflectance distribution functions. Those functions provide for the mentioned components and finally the assembly itself, the dependence on outgoing angle of the solar transmission and reflection for any incidence angle of the incoming solar radiation (usually in practice, the functions are separately given for the solar and the visible range of the spectrum). An advantage in building energy simulation of this approach, when compared to the use of old models for shading devices, is its precision. Another advantage comes from the use of the BSDF model in daylight analysis as well; then the ways energy efficiency and daylight analyses are done by simulation are unified. The disadvantage is the big number of required input values (not easily available) and the necessary long time involved in processing. Ways to simplify the BSDF approach have been sought after [7]. But the solutions proposed so far are limited; they only are applicable to the specific situations where the empirical fitting which is their basis is valid.

Comparisons have been made [8], to see the changes in the building energy calculated with the simulation software EnergyPlus when replacing the old models for shading devices with the more precise BSDF characterization. The difference reported in [8], where metal slats and screens were simulated, generally conforms to common intuition. For the annual cooling need, the old slat model system gives an underestimation of the results obtained with the BSDF approach (by a little more than $11 \%$ in the worst case in the particular facade and location case used in [8]). For the same annual cooling need, screens calculated according to the old model overestimate the result obtained with the BSDF approach (almost $8 \%$ is reported in [8] in their worst studied case). As expected, the old model (assuming a shading device material surface that is a perfectly diffuse scatterer for the solar radiation), is less correct for metal slats but appears less in error for screens.

An overview of the history until year 2004 of models for the interaction of slats with solar (also called optical in the literature) radiation is provided in [9]. After that, important contributions to the problem of modeling shading slats have been done at the University of Waterloo [10,11]. Also, as already mentioned, use of the more complicated and demanding BSDF procedure has been considered and tried. A very comprehensive study in which both energy efficiency of the building and daylighting of its interior space were pursued within the facade analysis is [12].

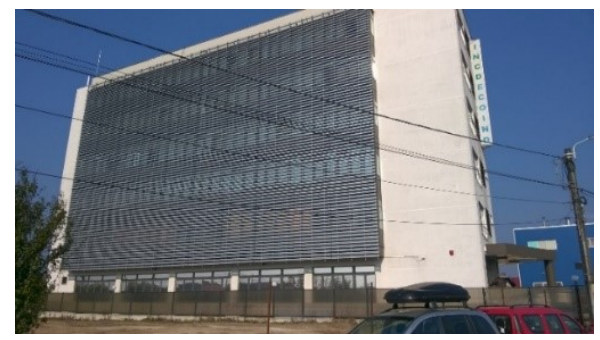

Fig. 1. The South facade of the studied office building, with the mounted aluminium louver shading system.
We present here, a hypothetical early design phase exercise to analyze various shading scenarios of the building facade. The shaded facade is judged based on its effect on the yearly energy performance of the "corresponding" part of the building. More exactly, considering a region "in the middle" of the facade of our building, we calculate by simulation the annual energy consumption (also called use) of the interior space (room) behind that facade region. The only surface for the space in question that allows heat transfer is its facade; all its other walls together with its floor and ceiling are considered adiabatic (that is, to simplify the analysis, adjacent spaces are taken to have the same interior temperature as the simulated space).

The simulation is done with the calculation engine EnergyPlus using the old models for shading slats and shading screens. 5 main situations (scenarios) are compared: one is the case when the facade is unshaded and the rest of 4 are shading scenarios. In 2 of them shading is provided by different subtypes of exterior slats (the analyzed slats are metallic and of big size, also called louvers) and in the remaining 2, shading is realized using different exterior flexible screens of the mesh type (not rigid screens of the panel-with-holes type).

We are aware the results we get from the calculation have not the precision of a BSDF approach. But using energy efficiency results together with other design considerations (like preference for a flexible shading strategy instead of an inflexible one and of course preference for the less expensive solution), some conclusions can be drawn that may prove useful. A more in-depth but more complicated analysis (that is not done here and that will likely use BSDF models) can be done in case of the combined target of both energy efficiency and daylighting.

\section{Method}

For the intended calculation by simulation we have chosen the tool COMFEN [13], made by Lawrence Berkeley National Laboratory, whose calculation engine is the building energy simulation software EnergyPlus [14]. The reasons for our decision were the simplicity and free availability of the tool.

As we mentioned, this very quick analysis is post factum: the analyzed building facade has already a mounted louver shading system. The material the louvers are made from is aluminum and they are Z-shaped. Fig. 2, a cross-section drawn by the architect, shows in addition to the reflective slats themselves (overlaid in red), some additional features related to the way the slats are attached to other structures. Those additional features are ignored in the old model used by EnergyPlus to calculate slat-solar radiation interaction. That old model was proposed by Simmler \& al $[15,6]$.

Actually, even the real Z-shape slats without the attaching features present a more complicated situation than the old model of the slat system in EnergyPlus. That model is a series of one-segment identical slats that do not have the 2 short segments (the ends) of our Z-shape red 
slats in Fig. 2. So, first we have to replace the real Z slats with the "equivalent" one-segment slats to use as the EnergyPlus model. The best "equivalent" we could think of was the green one-segment slat series in Fig. 2. That green slat arrangement preserves the cut-off angle of the red Z-shape slat system (the cut-off angle is the lowest profile angle producing facade obturation for direct solar rays). In other words, the arrangement preserves the same ratio between facade area that receives direct solar rays (not interacting with the slats) and the facade area in shadow (the incoming solar rays are considered parallel). So, based on the above equivalence, we derived the length and tilt angle of the green slats (the interspace between green slats remains equal to the interspace between the real, red slats, see Fig. 2).

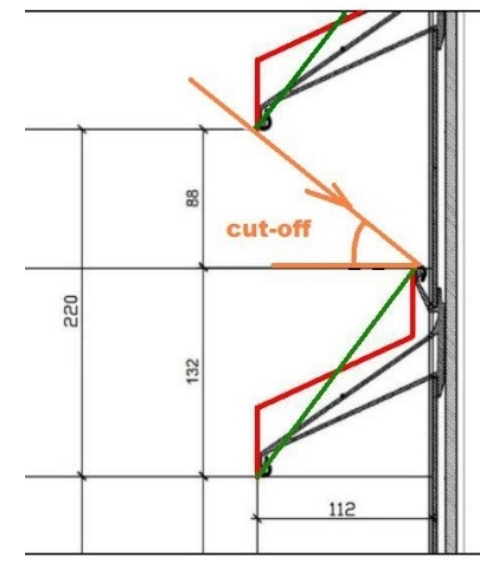

Fig. 2. Drawing of cross section of the louver system (in black); the reflective surfaces of the real slats are covered in red Actually, both short ends of the $Z$ shape are not one-segment, each is actually a $U$ turn in reality; but the $U$ turns were simplified as shown to not clutter the image excessively. The green slats are the one-segment slat "equivalent" of the red slat series.

We are still not done with the preparation of the slat system to be used by COMFEN 4.1. Because this interface for EnergyPlus has just one type of slat-like shading systems, called Venetian blind. And for that type, there is a limitation in the maximum slat width it accepts: 3.5 inches, which converted to SI is about $89 \mathrm{~mm}$ (unfortunately, we could not find a way in COMFEN to convert from Imperial units to SI; so from here on, we state any quantity both in SI for reader's ease and in IP, which is the actual used input). So, what we did then, was to scale down the whole slat system until the green slat width (that is the length of the slat in a plane normal to its long axis which is horizontal), becomes 3.5 in (its original length is $170 \mathrm{~mm}$ or $6.69 \mathrm{in})$. This scale-down process preserves the slat tilt angle $\left(39^{\circ}\right)$ and the ratio of the two facade areas: one receiving directly solar rays and the other in shadow. We have not mentioned so far, any margin effects considered for the slat system. Said otherwise, slats are modeled as being long enough to provide the same shadow situation for any point of the analyzed region of the facade. After scale-down, the slat interspace is $115 \mathrm{~mm}$ (4.53 in).
There is one more limitation regarding the Venetian blind type, the only slat-like shading systems available in COMFEN 4.1: there is no possibility for the variation of the default distance from the outer surface of glazing ([16] concludes that distance should be optimized when designing a louver system).

Beside the geometrical quantities above, COMFEN also needs as input the thickness of the slat. After scaledown, that was taken $1.37 \mathrm{~mm}$ (0.05 in).

The used solar optical properties of the slat material, both in the solar and visible regions of the spectrum, for both direct and diffuse radiation, are: transmittance (front of slat) and transmittance (back of slat) 0 , reflectance (front of slat) and reflectance (back of slat) 0.7 .

The used infrared properties, referring to the radiation in the Far Infrared Region (FIR) of the spectrum, emitted by common objects on the earth surface (like buildings), are: transmittance (front and back of slat) 0 , emissivity (front of slat) 0.9 , emissivity (back of slat) 0.9 . The thermal conductivity of the slat material is $159 \mathrm{~W} / \mathrm{m} / \mathrm{K}$ $(92.03 \mathrm{Btu} / \mathrm{h} / \mathrm{ft} / \mathrm{F})$. All the previous values are already available for a certain exterior slat material in the small Shading system library COMFEN 4.1 comes with (the respective shading system is named Venetian blind exterior, in that Shading system library).

The abbreviated name of the system having the above properties will further be $V B$ in this paper. We also used a different slat material, made from "clear architectural aluminum" produced by Lorin Industries Inc. Its optical reflectance for all categories enumerated was taken 0.76 and its IR emissivity 0.73 [17]. This second type of blinds will be called further Venetian Blinds clear or in short, $V B$ clear.

The competitors for the two kinds of exterior slat shading were two exterior shading screens of the mesh type. The first has a mesh cell size of $1.5 \mathrm{~mm}$ and the second, a finer mesh with $1 \mathrm{~mm}$ its cell size (they are included in the built-in library of COMFEN 4.1 and are called there dark-colored medium mesh and dark-colored fine mesh respectively). Their solar and visible reflectance is 0.1 , emissivity is 0.9 and thermal conductivity is $0.29 \mathrm{~W} / \mathrm{m} / \mathrm{K}(0.17$ IP units). The short names used further for the two screens will be: screen and for the small cell mesh, fine screen.

COMFEN simulates a building space (room) whose all walls, floor and ceiling are adiabatic except its sole exterior wall. That exterior wall is some "central" or "middle" region of the facade in question, shown in Fig. 3. The necessary inputs for the facade of the room are facade width, height and room depth. In our case they are respectively $6 \mathrm{~m}(19.68 \mathrm{ft}), 2.95 \mathrm{~m}(9.68 \mathrm{ft})$ and $5.5 \mathrm{~m}$ $(18.04 \mathrm{ft})$, see Fig. 3. The resulted room floor area is 33 $\mathrm{m}^{2}$.

COMFEN has several predefined building types and the one chosen by us for the performed simulation is office (COMFEN 4.1 manual provides specific inputs that apply to this choice, like schedule). For the wall of the facade we considered a very good thermal resistance value of $3.8 \mathrm{~m}^{2} \mathrm{~K} / \mathrm{W}\left(21.75 \mathrm{ft}^{2} \mathrm{Fh} / \mathrm{Btu}\right)$. But the facade has a large glazed area, that is the start point of the problem to 
solve: shading it in an energy efficient manner (ideally, that would imply solar gains are allowed in when they are needed and kept out of the building when not).

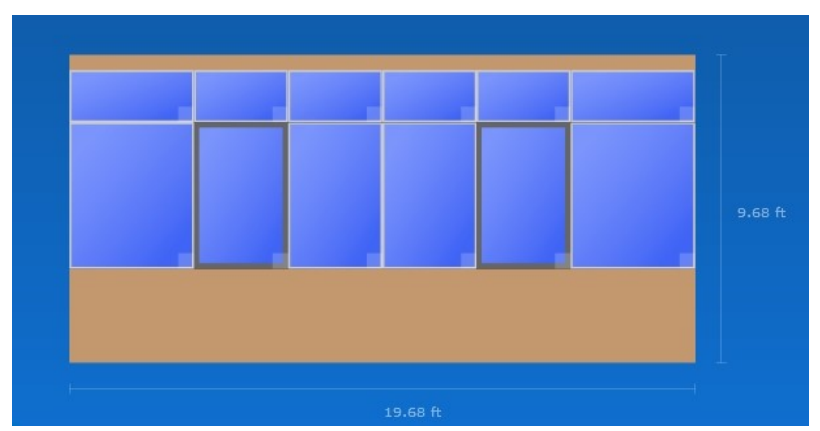

Fig. 3. Simplified 2D drawing of the simulated facade as drawn by COMFEN 4.1 .

The South oriented facade glazing consists of 2 glass layers (one of them low-e) and an insulated cavity between them filled with a mix of argon and air $(90 \%$ and $10 \%$ respectively). The described glazing is already present in the glazing library included in COMFEN 4.1. It is an Insulated Glazing Unit (IGU) whose transversal dimensions in millimeters, are 3-13-6 for the glass-cavityglass sequence. The thermal transmittance $U$ of the glazing is about $1.4 \mathrm{~W} / \mathrm{m}^{2} / \mathrm{K}\left(0.245 \mathrm{Btu} / \mathrm{h} / \mathrm{ft}^{2} / \mathrm{F}\right)$ and the Solar Heat Gain Coefficient (SHGC) is 0.469 (calculated according to the National Fenestration Rating Council procedure). The setback of the glazing (that is the depth of its outer surface measured from the exterior facade surface) is 0 in our case. The window frames used are from aluminum with a $U$ of 4.3 and $2.6 \mathrm{~W} / \mathrm{m}^{2} / \mathrm{K}(0.75$ $\mathrm{Btu} / \mathrm{h} / \mathrm{ft}^{2} / \mathrm{F}$ and $0.45 \mathrm{Btu} / \mathrm{h} / \mathrm{ft}^{2} / \mathrm{F}$ respectively) and an absorptivity of 0.9 . The two operable windows have a wider frame, of width $51 \mathrm{~mm}$ (2 in), see Fig. 3, but the frame for the rest of the glazing is $38 \mathrm{~mm}$ (1.5 in) wide between two panes. The operable windows have been assumed closed during the simulation (no natural ventilation through them has been considered).

Two separate occupancy cases were input: 3 persons in the room and then 4 .

The outdoor airflow per person was taken $30 \mathrm{mc} / \mathrm{h}$ $(17.66 \mathrm{cfm})$. And the lighting and office equipment loads were firstly considered: $10 \mathrm{~W} / \mathrm{m}^{2}\left(0.93 \mathrm{~W} / \mathrm{ft}^{2}\right)$ and $7 \mathrm{~W} / \mathrm{m}^{2}$ $\left(0.65 \mathrm{~W} / \mathrm{ft}^{2}\right)$ respectively.

It is known that unlike residential buildings, office buildings, especially big ones, have their energy use strongly affected by internal loads. In the past, the evolution of technology produced lamps and office equipment whose energy consumption was lower and lower. That thing can of course happen in the future too. So, in order to see the impact of the chosen lighting and equipment loads on our room energy use, in an optimistic hypothesis about the future, we ran again the computation by slashing the loads to smaller values: $0.65 \mathrm{~W} / \mathrm{ft}^{2}$ for lighting and $0.33 \mathrm{~W} / \mathrm{ft}^{2}$ for equipment. When the reduced loads are used, the 3 person case and 4 person case are respectively named shortly 3 person reduced and 4 person reduced.
COMFEN 4.1 has just one option for the HVAC equipment, a single (gas and electricity) packaged HVAC unit.

The Bucharest IWEC file was used for the weather data in the one-year simulation.

\section{Results}

Totals for an entire year of the energy use intensity (energy consumption divided by the space floor area) when the simulated room is occupied by 3 persons are shown in Fig. 4 for the 5 facade shading scenarios. The initial loads have been input and all shading devices are permanently deployed (the case is named by us, 3 person). As it can be seen, COMFEN automatically computes four parts of the energy consumption of the simulated room: the energy for heating, for cooling, for lighting and the energy consumption of the fans (of the HVAC unit).

The simulation was repeated for the reduced loads. see Fig. 4'.

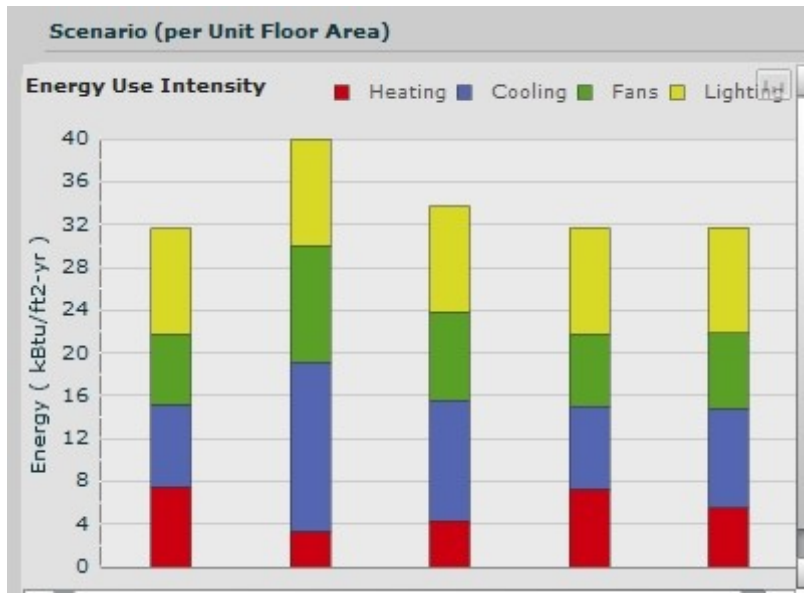

Fig. 4. Annual energy use per room floor area unit for the 3 person case, in the following order (from left to right): $V B, n o-$ shading, screen, VB clear, fine screen.

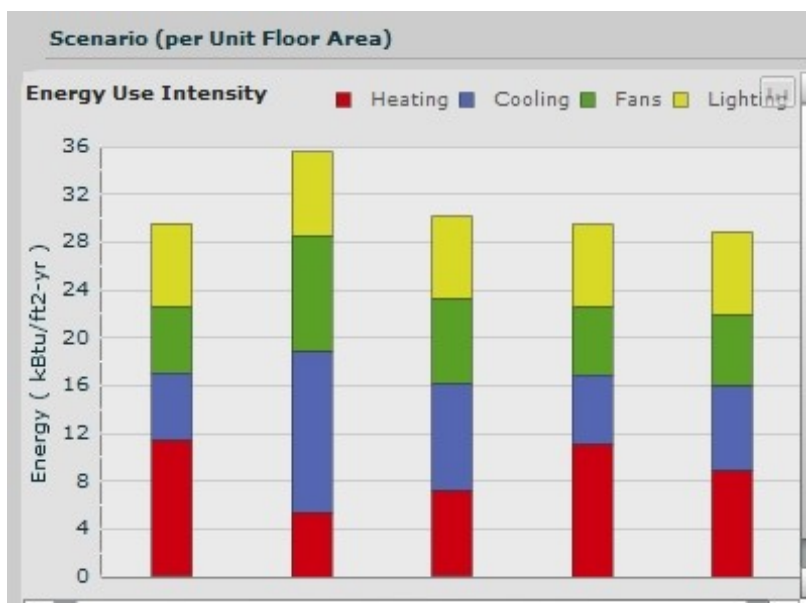

Fig. 4'. Annual energy use per room floor area unit for the 3person reduced case, in the following order (from left to right): $V B$, no-shading, screen, VB clear, fine screen. 
We are rather interested in relative differences between the simulated cases than in the exact numbers themselves. Is is obvious the worst case is no-shading for the facade throughout the year. Next comes the less fine shading mesh. But the other mesh is successfully competing with the slat systems in terms of annual energy performance. Lighting energy use is the same in all cases (it is a fixed number per floor area unit). The most important differences between the two slat cases and the small cell mesh are illustrated by the length of the red and blue bars, that is in the heating and cooling energy use respectively. As expected, the louvers appear to perform better during the cooling season but worse in the heating season.

Fig. 5 and Fig. 6 respectively show, for the slat shading systems and the screens, the monthly totals of energy use intensity (its components, are again featured as red, blue, green and yellow bars as in Fig. 4 and Fig. 4'). The no shading year-round case is included for comparison. According to common intuition, the best solution when heating is required is to have the facade unshaded. The uncovered facade has obviously the smallest heating energy use all the time, because of its unobstructed access for solar gains.

This of course leads someone to think of the possibility of a flexible shading strategy: having the shading devices removed during some cold months in order to receive more solar gains. That is not a problem with the not so expensive screen type systems; but it is too troublesome and expensive for the louver system that is always kept in place. So, because we could not schedule in COMFEN 4.1 to have the shading devices on for a certain period of the year and off for the rest of it, we made some combinations of monthly totals: namely we took some of the cold months from the no shading simulation and other months of the year from the fine screen simulation. For each month, the best result of the two simulations was chosen. Doing that, a not too big improvement is obtained, something in the interval 1.5$2 \%$ (initial loads situation) when compared to the yearround fine screen shading case. But when the loads are reduced as mentioned, the improvement is about $4 \%$ (this case is named by us 3 person reduced).

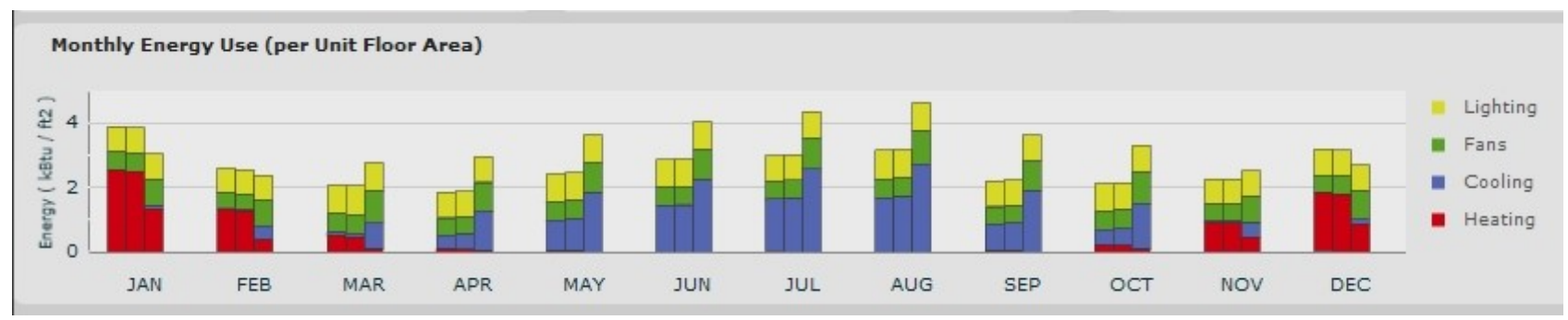

Fig. 5. Monthly energy use per room floor area unit for the 3 person case, in the following order: VB, VB clear, no-shading.

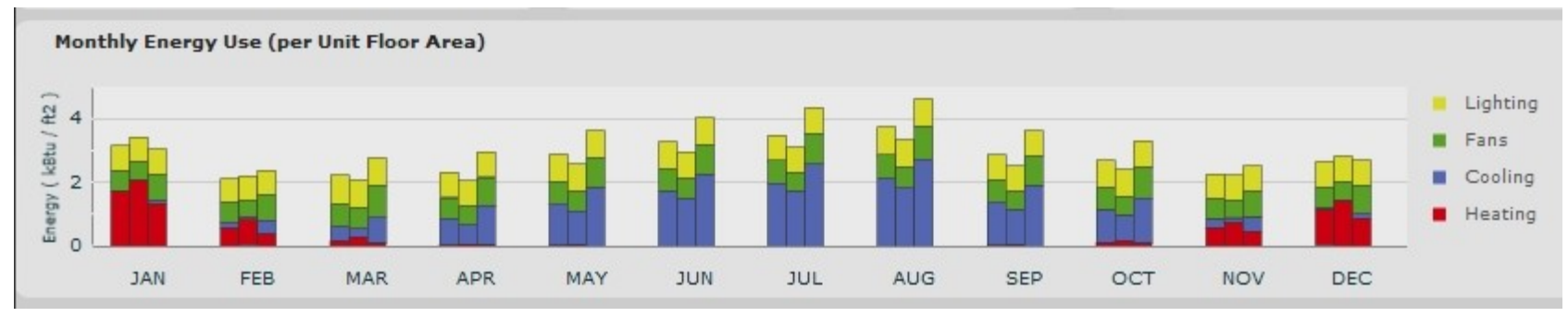

Fig. 6. Monthly energy use per room floor area unit for the 3-person case, in the following order: screen, fine screen, no-shading.

The same thing has been done considering 4 people in the room. The year totals are somewhat bigger. The combination of 12 months, some having the fine screen shading system off and others on, gives a better improvement compared to the year-round fine screen scenario: above $2 \%$ when the initial loads are input and in the interval $4.5-5 \%$ when the inputs are the reduced loads.

\section{Conclusion}

The presented brief analysis of the South facade of a midrise office building in Bucharest compared the energy efficiency of shading the facade in four ways: by two exterior metal slat systems and by two exterior screens of the mesh type. The computation done did not consider the glare protection for the occupants. There are interior slat blinds in the real building analyzed here that are used for that purpose and are manually operated. But they were ignored by us to strongly simplify the analysis.

Also, for simplicity and speed of the analysis process, the old models for how slats and screens interact with the solar radiation were used in the simulations (instead of the newer, more complicated approach of using BSDF functions for the glazing and shading system assembly). For the climate of Bucharest, common to many cities in Romania (continental, with big temperature differences between summer and winter with cold winters and many days in summer hot enough to require intensive cooling, 
especially in office buildings), the results of our computation show that a fine screen can be, year-round, as energy efficient as a fixed louver system. That is encouraging because the louver system is of course more expensive. It is very unlikely the conclusion for screen preference (based strictly on energy efficiency and cost point of view) will be overturned by repeating the calculation with BSDF functions instead of the old slat and screen models mentioned above (let's remember that according to common intuition, when compared to BSDF in [7], the old slat model underestimated the cooling need; besides the old model for screens overestimated it).

A second obvious advantage of the screen solution is the fact its energy performance can be further increased compared to the situation where the screen is in place the whole year. That is achieved by removing the screen during the cold season when passive solar gains are needed inside the building.

Another pro for the screen solution comes from the likely high cost to keep the louver system clean (and consequently functional) during the winter, when snow is a common thing in Bucharest. As regards dirt in other seasons than winter, both louvers and screens are systems affected by it. This again is something not factored in by the computation done.

\section{References}

1. Torcellini P., Pless S., Deru M., Griffith B., Long N. and R. Judkoff, Leson Learned from Case Studies of Six High-Performance Buildings, Technical Report NREL/TP-550-37452 June 2006

2. Dubois Marie-Claude, Solar Shading and Building Energy Use, A Literature Review, Part 1, Report TABK--97/3049, Lund University, Department of Building Science, Lund Institute of Technology, Sweden, 1997 ;

3. Dubois Marie-Claude, Solar Shading for Low Energy Use and Daylight Quality in Offices. Simulations, Measurements and Design Tools, Report No TABK--01/1023, Lund University, Department of Construction and Architectur, Lund Institute of Technology, Sweden, 2001 ;

4. Klems J.H., ASHRAE Transactions (1994 I), vol. 100, pt. 1, pp 1065-1072, A New Method for Predicting the Solar Heat Gain of Complex Fenestration Systems: I. Overview and Derivation of the Matrix Layer Calculation;

5. Klems J.H., ASHRAE Transactions (1994 I), vol. 100, pt. 1, pp 1065-1072, A New Method for Predicting the Solar Heat Gain of Complex Fenestration Systems: II. Detailed Description of the Matrix Layer Calculation;

6. EnergyPlus Engineering Reference, https://energyplus.net/sites/default/files/pdfs_v8.3.0 /EngineeringReference.pdf;

7. Hauer Martin, Geisler-Moroder David,Hiller Marion,Thermal modelling of complex fenestration systems - Comparison of a BSDF-based model with
A fixed-in-place louver requires special structural design for its support (attach) system as it is heavy and affected by wind loads. On the other hand, the screens of the mesh type are more prone to wear and tear due to weather and in general outdoor exposure.

It seems the main consideration to decide for a fixed louver system (which is not desirable in the heating season as it lowers the passive solar gains of the building) is the beauty acquired by integrating it within the facade. We think we understand architects' love for iconic building facades and our analyzed building is such an example in our opinion. But leaving the aesthetic reason aside, the final conclusion of our simple and quick analysis clearly seems to be that screens win when the main target is strictly energy efficiency for the best cost.

When daylighting is a primary concern too, then probably the way to go in the facade design analysis is employing the BSDF approach. A simple manner to do that is still an open topic for future research in the field.

The authors thank Mr. Viorel Patroescu for close collaboration and for providing details about the building and its shading system.

simplified approaches,IBPSA Conference 2015, www.ibpsa.org/proceedings/BSA2015/9788860460 745 19.pdf;

8. O. Dartevelle1; G. Lethé2; A. Deneyer2; M. Bodart1, THE USE OF BI-DIRECTIONAL SCATTERING DISTRIBUTION FUNCTIONS FOR SOLAR SHADING MODELLING IN DYNAMIC THERMAL SIMULATION: A RESULTS COMPARISON, poster "CISBAT2013:Clean Technology for Smart Cities and Buildings", Lausanne (du 04/09/2013 au 06/09/2013),

https://dial.uclouvain.be/pr/boreal/object/boreal:13 5232

https://www.wtcb.be/?dtype $=$ research $\&$ doc $=$ cisbat 2013 full.pdf\&lang=en;

9. Chanvit Chantrasrisalai and Daniel E. Fisher, COMPARATIVE ANALYSIS OF ONEDIMENSIONAL SLAT-TYPE BLIND MODELS, IBPSA USA Conference 2004, https://ibpsausa.org/index.php/ibpusa/article/download/108/93;

10. Wright, J.L., Kotey, N.A. 2006. Solar Absorption by Each Element in a Glazing/Shading Layer Array, ASHRAE Transactions, Vol. 112, Pt. 2. pp. 3-12;

11. Wright, J.L. 2008. Calculating Centre-Glass Performance Indices of Glazing Systems with Shading Devices, ASHRAE Transactions, Vol. 114, Pt. 2;

12. Sabine Hoffmann, Eleanor S. Lee, Andrew McNeil, Luis Fernandes, Dragan Vidanovic, Anothai Thanachareonkit, Balancing daylight, glare, and 
energy-efficiency goals : An evaluation of exterior coplanar shading systems using complex fenestration modeling tools, Energy and Buildings 112 (2016): 279-298, published as LBNL report, Energy Technologies Area, November 2015, LBNL-1005092;

13. https://windows.lbl.gov/software/comfen;

14. https://energyplus.net/;

15. Simmler, H., U. Fischer and F. Winkelmann. 1996. Solar-Thermal Window Blind Model for DOE-2.
Lawrence Berkeley National Laboratory, Simulation Research Group internal report, (unpublished);

16. Cory Joseph Brennan, Analysis of passive louver shading systems and impact on interior environment, Masters Theses 2012, Missouri University of Science and Technology;

17. https://continuingeducation.bnpmedia.com/courses/ lorin-industries-inc/anodized-aluminum-forarchitectural-applications/5/. 